\title{
Spectroscopic investigation of the dynamical behavior of the photoinduced phase transition of $\mathrm{Na}_{0.6} \mathrm{Co}_{1.3}\left[\mathrm{Fe}(\mathrm{CN})_{6}\right] \cdot 4 \mathrm{H}_{2} \mathrm{O}$
}

\author{
T. Yamauchi and A. Nakamura \\ Department of Applied Physics, Nagoya University, Nagoya 464-8603, Japan \\ Y. Moritomo* \\ Department of Physics, University of Tsukuba, Tsukuba 305-8571, Japan
}

T. Hozumi, K. Hashimoto, and S. Ohkoshi

Department of Applied Chemistry, University of Tokyo, Tokyo 113-8656, Japan

(Received 25 July 2005; revised manuscript received 18 October 2005; published 14 December 2005)

\begin{abstract}
The dynamics of the photoinduced phase transition (PIPT) has been investigated for the Co-Fe cyanides film, $\mathrm{Na}_{0.6} \mathrm{Co}_{1.3}\left[\mathrm{Fe}(\mathrm{CN})_{6}\right] \cdot 4 \mathrm{H}_{2} \mathrm{O}$, by means of the transient absorption spectroscopy. At low temperatures $(\lesssim 150 \mathrm{~K})$, the compound shows the permanent PIPT from the low-spin phase [LS phase: $\mathrm{LS} \mathrm{Co}^{3+}$ $\left.\left(t_{2 \mathrm{~g} \uparrow}^{3} t_{2 \mathrm{~g}\rfloor}^{3}\right)-\mathrm{LS} \mathrm{Fe}{ }^{2+}\left(t_{2 \mathrm{~g} \uparrow}^{3} t_{2 \mathrm{~g}\rfloor}^{3}\right)\right]$ to the high-spin phase [HS phase; HS $\left.\mathrm{Co}^{2+}\left(t_{2 \mathrm{~g}\urcorner}^{3} t_{2 \mathrm{~g}\rfloor}^{2} e_{\mathrm{g} \uparrow}^{2}\right)-\mathrm{LS} \mathrm{Fe} \mathrm{Fe}^{3+}\left(t_{2 \mathrm{~g} \uparrow}^{3} t_{2 \mathrm{~g} \downarrow}^{2}\right)\right]$. We have found that the film shows the transient PIPT into the HS phase above $\sim 170 \mathrm{~K}$, and the lifetime $\tau_{\mathrm{PI}}$ of the photoinduced phase exponentially decreased from $10 \mathrm{~ms}$ at $170 \mathrm{~K}$ to $\sim 100 \mu$ s at $260 \mathrm{~K}$. In the early stage $(\Delta t \leqslant 200 \mathrm{~ns})$ of the PIPT, we further have observed a characteristic photoinduced absorption band ( $Y$ band) and ascribed the band to the $\mathrm{LS} \mathrm{Co}{ }^{2+}\left(t_{2 \mathrm{~g} \uparrow}^{3} t_{2 \mathrm{~g} \downarrow}^{3} e_{\mathrm{g} \uparrow}^{1}\right)$ state.
\end{abstract}

DOI: 10.1103/PhysRevB.72.214425

PACS number(s): 68.18.Jk, 42.50.Md

\section{INTRODUCTION}

The photoinduced phenomena ${ }^{1}$ have been extensively investigated both from the fundamental and technical points of view. In an extreme case, the photoexcitation causes the macroscopic structural change, or the so-called photoinduced phase transition (PIPT). Thus far, a long list of researchers reported the persistent PIPTs in spin-crossover complexes, ${ }^{2-5}$ transition metal cyanides, ${ }^{6-11}$ mixed-valence gold complex, $\mathrm{Cs}_{2} \mathrm{Au}_{2} \mathrm{Br}_{6}{ }^{12}$ iodine-bridged binuclear $\mathrm{Pt}$ compounds, ${ }^{13}$ organic radical crystal, TTTA (1,3,5-trithia-2,4,6-triazapentalenyl) ${ }^{14}$ polydiacetylene crystal, ${ }^{15}$ and so on. In these systems, the photoinduced lattice structure is permanently maintained after the photoexcitation stops. On the other hand, Collet et al. ${ }^{16}$ have performed a time-resolved x-ray-diffraction measurement in organic charge-transfer salts, TTF-CA (tetrathiafulvalenep-chloranil). They observed a transient PIPT phenomenon: the photoinduced phase transition from the neutral phase to ionic phase completed in $0.5 \mathrm{~ns}$, but the photoinduced (PI) phase is not metastable and recovers to the ground state (neutral phase) within $1 \mathrm{~ms}$. Here, we stress that the repetition behavior of the transient PIPT is quite important because it enables us to investigate the dynamical behavior by means of the transient absorption spectroscopy.

Among the photosensitive materials, the Co-Fe cyanides, whose chemical formula is $A_{x} \mathrm{Co}\left[\mathrm{Fe}(\mathrm{CN})_{6}\right]_{y} \cdot \mathrm{zH}_{2} \mathrm{O} \quad(A$ $=\mathrm{Na}, \mathrm{K}, \mathrm{Rb}, \mathrm{Cs})$, have been attracting renewed interest of material scientists because they show a photoinduced magnetization $^{6,7}$ as well as photoinduced structural change. ${ }^{10}$ For example, Sato et al. ${ }^{6}$ reported enhancement of magnetization in $\mathrm{K}_{0.14} \mathrm{Co}\left[\mathrm{Fe}(\mathrm{CN})_{6}\right]_{0.71} \cdot 4.93 \mathrm{H}_{2} \mathrm{O}$ by irradiation of a red light $(660 \mathrm{~nm})$ at $5 \mathrm{~K}$ and suppression of magnetization by irradiation of a blue light $(450 \mathrm{~nm})$ at $5 \mathrm{~K}$. In addition, a thin films of Co-Fe cyanide, which is indispensable for a reliable transient absorption spectroscopy, can be grown on a $\mathrm{SnO}_{2}$-coated glass by the electrochemical reduction technique. ${ }^{18-20}$ Thus, we have chosen the Co-Fe cyanide as a target material for the detailed investigation on the dynamical behavior of the PIPT.

Crystallographically, the Co-Fe cyanides belong to the fcc group $(F m \overline{3} m ; Z=4)$, in which $\mathrm{Co}$ and Fe ions form a rocksalt-type (NaCl-type) network with sharing cyano $\left(\mathrm{CN}^{-}\right)$ moieties. ${ }^{21}$ Parts of the $\mathrm{Fe}(\mathrm{CN})_{6}$ sites, however, are vacant and are replaced by six waters $\left(\mathrm{H}_{2} \mathrm{O}\right)$. Most of the Co-Fe cyanides show a first-order phase transition from the lowspin (LS) phase [LS phase: LS $\mathrm{Co}^{3+}\left(t_{2 \mathrm{~g} \uparrow}^{3} t_{2 \mathrm{~g} \downarrow}^{3}\right)-\mathrm{LS} \mathrm{Fe}^{2+}$ $\left.\left(t_{2 \mathrm{~g} \uparrow}^{3} t_{2 \mathrm{~g} \downarrow}^{3}\right)\right]$ to the high-spin (HS) phase (HS phase: $\mathrm{HS} \mathrm{Co}^{2+}$ $\left.\left(t_{2 \mathrm{~g} \uparrow}^{3} t_{2 \mathrm{~g} \downarrow}^{2} e_{\mathrm{g} \uparrow}^{2}\right)-\mathrm{LS} \mathrm{Fe}^{3+}\left(t_{2 \mathrm{~g} \uparrow}^{3} t_{2 \mathrm{~g} \downarrow}^{2}\right)\right)$ as temperature increases. This thermally induced phase transition accompanies a significant increase of the lattice constant $a$ from $\approx 9.9 \AA$ in the LS phase to $\approx 10.3 \AA$ in the HS phase. At low temperatures $(\lessgtr 150 \mathrm{~K})$, a similar phase transition from the LS phase to the HS phase is induced by photoexcitation, ${ }^{10,11}$ which forcedly transfers an electron from the $\mathrm{LS} \mathrm{Fe}^{2+}$ site to the $\mathrm{LS}$ $\mathrm{Co}^{3+}$ site. Then, the photo-induced magnetism ${ }^{6,7}$ is rationally ascribed to the persistent PIPT from the (nonmagnetic) LS phase to the HS phase. The PI phase, however, melts into the LS phase as temperature increases above $\sim 150 \mathrm{~K}$.

In this paper, we have investigated the dynamical behavior of the PIPT of the Co-Fe cyanides film, $\mathrm{Na}_{0.6} \mathrm{Co}_{1.3}\left[\mathrm{Fe}(\mathrm{CN})_{6}\right] \cdot 4 \mathrm{H}_{2} \mathrm{O}$, by means of the transient absorption spectroscopy. At high temperatures, we observed a broad absorption band located at $\sim 2.4 \mathrm{eV}$, indicating the transient PIPT into the HS phase. The lifetime $\tau_{\mathrm{PI}}$ of the PI phase exponentially decreases from $10 \mathrm{~ms}$ at $170 \mathrm{~K}$ to $\sim 100 \mu \mathrm{s}$ at $260 \mathrm{~K}$. In the early stage $(\Delta t \leqslant 120 \mathrm{~ns})$ of the PIPT, we further have observed a characteristic photoinduced 

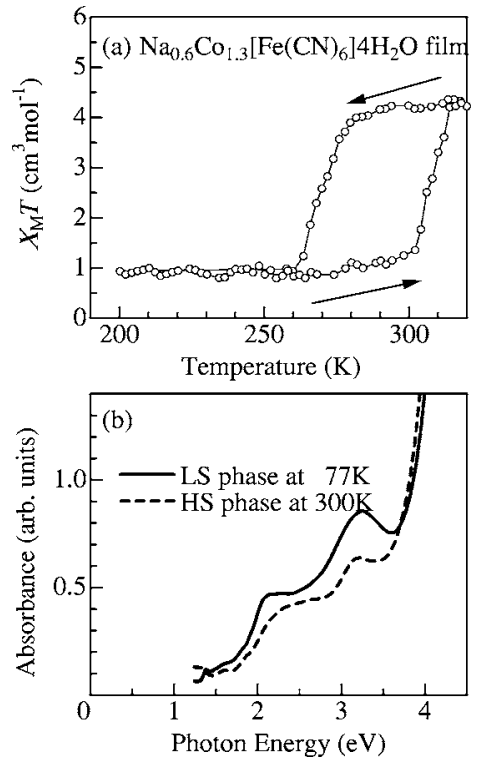

FIG. 1. (a) Temperature dependence of $\chi_{\mathrm{M}} T$ of $\mathrm{Na}_{0.6} \mathrm{Co}_{1.3}\left[\mathrm{Fe}(\mathrm{CN})_{6}\right] \cdot 4 \mathrm{H}_{2} \mathrm{O}$, where $\chi_{\mathrm{M}}$ is the magnetic susceptibility. (b) Absorption spectra at $77 \mathrm{~K}$ in the LS phase (solid curve) and at $300 \mathrm{~K}$ in the $\mathrm{HS}$ phase (broken curve).

absorption band ( $Y$ band) at $\approx 1.7 \mathrm{eV}$, and ascribed the band to the $\operatorname{LS~} \mathrm{Co}^{2+}\left(t_{2 \mathrm{~g} \uparrow}^{3} \uparrow_{2 \mathrm{~g} \downarrow}^{3} e_{\mathrm{g} \uparrow}^{1}\right)$ state.

\section{EXPERIMENTAL}

\section{A. Sample preparation and characterization}

The Co-Fe cyanide film was prepared on a $\mathrm{SnO}_{2}$-coated glass according to the procedure described elsewhere. ${ }^{18}$ With use of a superconducting quantum interfence device (SQUID) magnetometer, we have measured temperature dependence of the magnetic susceptibility $\chi_{\mathrm{M}}$ of the film. Figure 1(a) shows temperature dependence of $\chi_{\mathrm{M}} T$ of the film, which is a crude measure for the effective spin moment. As seen in Fig. 1(a), the film shows the LS-to-HS transition at $T_{\mathrm{c} \uparrow}=306 \mathrm{~K}$ in the warming run, and at $T_{\mathrm{c} \downarrow}=268 \mathrm{~K}$ in the cooling run. Based on the thusly determined transition temperatures, ${ }^{22}$ the chemical composition of the film was estimated at $\mathrm{Na}_{0.6} \mathrm{Co}_{1.3}\left[\mathrm{Fe}(\mathrm{CN})_{6}\right] \cdot 4 \mathrm{H}_{2} \mathrm{O}$.

We show, in Fig. 1(b), absorption spectra of the Co-Fe cyanide film at $77 \mathrm{~K}$ in the LS phase and at $300 \mathrm{~K}$ in the HS phase. In both the phases, two characteristic peak structures are observed below $\sim 3.5 \mathrm{eV}$. The LS-HS phase transition significantly modifies the absorption spectrum in the visible region because of the concomitant cooperative charge transfer from the $\mathrm{Fe}^{2+}$ site to the $\mathrm{Co}^{3+}$ site. Figure 2 shows the magnified absorption spectra in the visible region. The spectrum indicated by broken curve stands for the photoinduced (PI) phase at $80 \mathrm{~K}$, which was measured after photoexcitation by a halogen lamp for several minutes. The photoexcitation suppresses the absorption in the energy region of $2-3 \mathrm{eV}$. The spectral profile of the PI phase (broken curve) resembles with that at $300 \mathrm{~K}$ in the $\mathrm{HS}$ phase (thin solid curve ${ }^{17}$ ), indicating that PI phase has the same electronic configuration as the HS phase. ${ }^{18}$

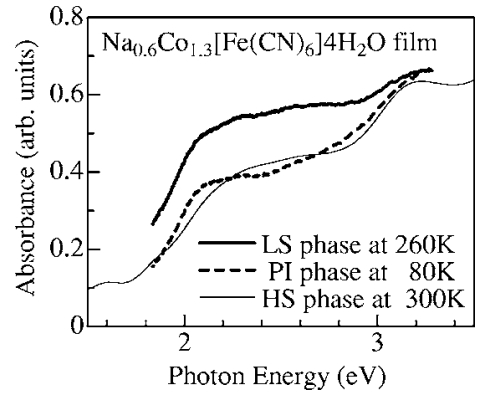

FIG. 2. Magnified absorption spectra of $\mathrm{Na}_{0.6} \mathrm{Co}_{1.3}\left[\mathrm{Fe}(\mathrm{CN})_{6}\right] \cdot 4 \mathrm{H}_{2} \mathrm{O}$ at $260 \mathrm{~K}$ in the LS phase (solid curve) and at $300 \mathrm{~K}$ in the $\mathrm{HS}$ phase (thin solid curve). A broken curve stands for the PI phase at $80 \mathrm{~K}$.

\section{B. Time-resolved absorption spectroscopy}

We used a nanosecond optical parametric oscillator (OPO) system pumped by a YAG laser $(355 \mathrm{~nm}, 10 \mathrm{~Hz})$ as an excitation source. The pulse width was 3-5 ns. For the time-resolved spectroscopy, light from a halogen lamp was focused on the sample film and the transmitted light was detected with a gatable charge-coupled device (CCD) camera attached at the output stage of a grating monochrometer. In the measurement of the small $\Delta t$ spectra, we put a polarizer in front of the monochrometer in order to eliminate the intense scattering from the excitation light. The time resolution of the system was 12 ns.

In order to obtain the overall temporal behavior of the photoinduced absorption change, we used continuous-wave lasers, e.g., He-Ne laser $(1.85 \mathrm{eV})$ and yttrium aluminum garnet (YAG) laser $(2.33 \mathrm{eV})$, as a probe light source. The intensity change $T_{1.85 \mathrm{eV}}\left(T_{2.33 \mathrm{eV}}\right)$ of the transmitted light was detected with a P-intrinsic-N (PIN) photodiode, and the temporal behavior of $T_{1.85 \mathrm{eV}}\left(T_{2.33 \mathrm{eV}}\right)$ was accumulated with a digital oscilloscope.

\section{RESULTS AND DISCUSSION}

\section{A. Transient photoinduced phase transition}

Figure 3(a) shows the differential absorption spectra of $\mathrm{Na}_{0.6} \mathrm{Co}_{1.3}\left[\mathrm{Fe}(\mathrm{CN})_{6}\right] \cdot 4 \mathrm{H}_{2} \mathrm{O}$ at $260 \mathrm{~K}$. At $\Delta t=500 \mathrm{~ns}$, the photoexcitation significantly suppresses the absorption in the energy region of $2-3 \mathrm{eV}$. The magnitude of the differential absorption decreases as the delay time $\Delta t$ increases, and eventually, the signal disappears at $\Delta t=500 \mu \mathrm{s}$. The lower panel of Fig. 3 shows the differential absorption spectra of the PI phase at $80 \mathrm{~K}$, which was measured after photoexcitation by a halogen lamp for several min.. The profile of the transient absorption spectra [Fig. 3(a)] resembles that of the PI phase [Fig. 3(b)]. This clearly indicates that the photoexcitation on the Fe-Co cyanide film transiently creates the HS phase.

Figure 4 shows temporal behavior of the magnitude of the transient absorption at $260 \mathrm{~K}$. The vertical axis (mass fraction $\phi$ ) was normalized by the area of the differential absorption spectra of the PI phase. [see Fig. 3(b)] A broken curve is the best-fitted result with a exponential function, $\phi$ 

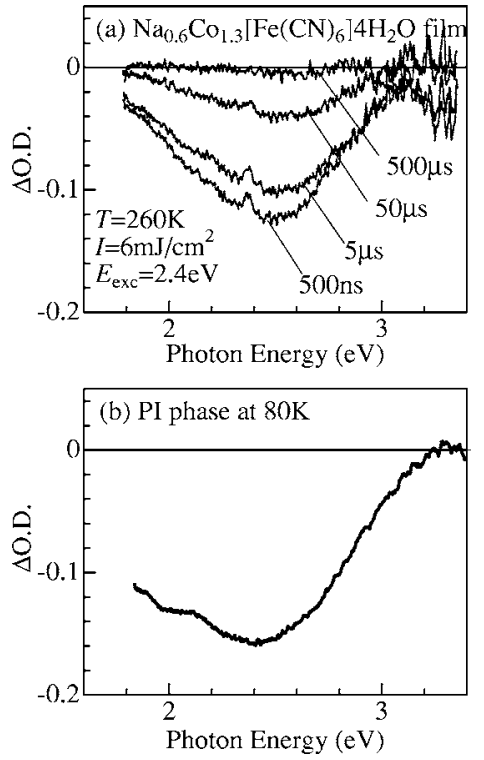

FIG. 3. (a) Differential absorption spectra of $\mathrm{Na}_{0.6} \mathrm{Co}_{1.3}\left[\mathrm{Fe}(\mathrm{CN})_{6}\right] \cdot 4 \mathrm{H}_{2} \mathrm{O}$ at $260 \mathrm{~K}$. The pulse energy and photon energy of the excitation light were $6 \mathrm{~mJ} / \mathrm{cm}^{2}$ and $2.4 \mathrm{eV}$, respectively. (b) Differential absorption spectra of the PI phase at $80 \mathrm{~K}$, which was measured after photoexcitation by a halogen lamp for several minutes.

$=\phi_{0} \exp [-(\Delta t / \tau)]$. The PI HS phase relaxes into the LS ground state with the lifetime $\tau_{\mathrm{PI}}$ of $50 \mu \mathrm{s}^{23}$

The initial mass fraction $\phi_{0}$ of the PI phase shows a notable photon energy dependence, as shown in Fig. 5. The excitation spectrum (open circles) shows a broad maximum at $\approx 2.4 \mathrm{eV}$, and does not trace the absorption spectra of the LS phase (solid curve). This spectral difference between the excitation and absorption spectrums clearly excludes the conventional heating effect as an origin for the observed transient PITP phenomenon. The peak position of the excitation spectrum roughly coincides with first peak of the absorption spectrum. Based on the ab initio cluster calculation, Kawamoto et al. ${ }^{24}$ assigned the first absorption peak to the dipole-allowed charge-transfer excitation from the $\mathrm{LS} \mathrm{Fe}^{2+}$ $\left(t_{2 \mathrm{~g}}^{3} \uparrow_{2 \mathrm{~g} \downarrow}^{3}\right)$ site to the $\mathrm{LS} \mathrm{Co}^{3+}\left(t_{2 \mathrm{~g}}^{3} t_{2 \mathrm{~g} \downarrow}^{3}\right)$ site. Then, the excita-

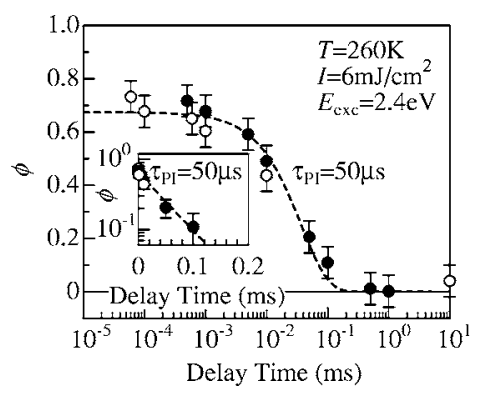

FIG. 4. Mass fraction $\phi$ of the PI phase of $\mathrm{Na}_{0.6} \mathrm{Co}_{1.3}\left[\mathrm{Fe}(\mathrm{CN})_{6}\right] \cdot 4 \mathrm{H}_{2} \mathrm{O}$ at $260 \mathrm{~K}$. The pulse energy and photon energy of the excitation light were $6 \mathrm{~mJ} / \mathrm{cm}^{2}$ and $2.4 \mathrm{eV}$, respectively. A broken curve is the best-fitted result with a exponential function, $\phi=\phi_{0} \exp [-(\Delta t / \tau)]$. Open and filled circles were the data obtained at the different runs. Inset shows a single logarithm plot of $\phi$ againt $\Delta t$.

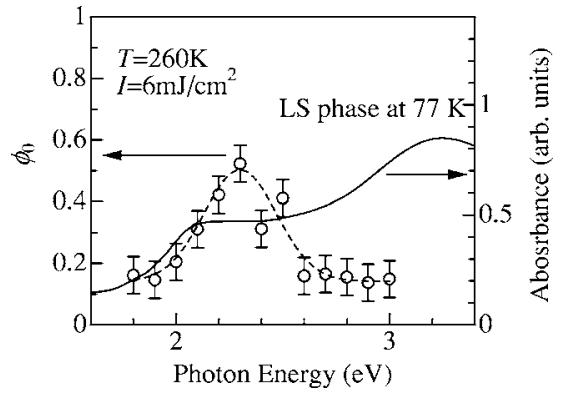

FIG. 5. Photon energy dependence of the initial mass fraction $\phi_{0}(\Delta t=500 \mathrm{~ns})$ of the PI phase of $\mathrm{Na}_{0.6} \mathrm{Co}_{1.3}\left[\mathrm{Fe}(\mathrm{CN})_{6}\right] \cdot 4 \mathrm{H}_{2} \mathrm{O}$ at $260 \mathrm{~K}$. A solid curve represents the absorption spectrum of the LS phase at $77 \mathrm{~K}$. The excitation energy was adjusted to $6 \mathrm{~mJ} / \mathrm{cm}^{2}$. A broken curve is merely a guide to the eyes.

tion spectrum suggests that the initial charge-transfer plays significant role in the PIPT of the Co-Fe cyanide. Here, we stress that the $\mathrm{LS} \mathrm{Co}^{3+}$ site is transferred to the $\mathrm{LS} \mathrm{Co}^{2+}$ $\left(t_{2 \mathrm{~g} \uparrow}^{3} t_{2 \mathrm{~g} \downarrow}^{3} e_{\mathrm{g} \uparrow}^{1}\right)$ state immediately after the photoexcitation. In order to complete the PIPT into the HS phase, however, the intersystem crossing from the LS Co ${ }^{2+}\left(t_{2 \mathrm{~g}}^{3} \uparrow_{2 \mathrm{~g} \downarrow}^{3} e_{\mathrm{g} \uparrow}^{1}\right)$ to the HS $\mathrm{Co}^{2+}\left(t_{2 \mathrm{~g} \uparrow}^{3} t_{2 \mathrm{~g} \downarrow}^{2} e_{\mathrm{g} \uparrow}^{2}\right)$ is indispensable.

We show in Fig. 6(a) temperature dependence of the lifetime $\tau_{\text {PI }}$ of the PI phase. These values were estimated by the least-squares fitting of the $\Delta T_{2.33 \mathrm{eV}}-\Delta t$ curve as $\Delta T_{2.33 \mathrm{eV}}$ $=A \exp \left[-\left(\Delta t / \tau_{\mathrm{PI}}\right)\right]$. As shown by the straight line in Fig. 6(a), the lifetime $\tau_{\text {PI }}$ of the PI phase obeys a thermalactivation low; $\tau_{\mathrm{PI}} \propto \exp (\Delta / T)$, where $\Delta(\approx 0.23 \mathrm{eV})$ is the activation energy. It may be interesting that the magnitude of $\Delta$ is the same order as the transition entropy $\Delta H$ $(\approx 0.17 \mathrm{eV})$ of an analogous system $\mathrm{RbMn}\left[\mathrm{Fe}(\mathrm{CN})_{6}\right] .{ }^{25} \mathrm{The}$ magnitude of $\phi_{0}$ slightly increases with temperature. This is


FIG. 6. Temperature dependence of (a) the lifetime $\tau_{\text {PI }}$ and (b) the initial mass fraction $\phi_{0}$ (extrapolation) of the PI phase of $\mathrm{Na}_{0.6} \mathrm{Co}_{1.3}\left[\mathrm{Fe}(\mathrm{CN})_{6}\right] \cdot 4 \mathrm{H}_{2} \mathrm{O}$ at $260 \mathrm{~K}$. The pulse energy and photon energy of the excitation light were $6 \mathrm{~mJ} / \mathrm{cm}^{2}$ and $2.4 \mathrm{eV}$, respectively. A broken curve in (a) is the best-fitted result with a exponential function. 




FIG. 7. Differential absorption spectra of $\mathrm{Na}_{0.6} \mathrm{Co}_{1.3}\left[\mathrm{Fe}(\mathrm{CN})_{6}\right] \cdot 4 \mathrm{H}_{2} \mathrm{O}$ at $260 \mathrm{~K}$. The pulse energy and photon energy of the excitation light were $5 \mathrm{~mJ} / \mathrm{cm}^{2}$ and $2.33 \mathrm{eV}$, respectively. An upward arrow indicates a photoinduced absorption band ( $Y$ band).

probably because the free energy of the PI phase approaches to that of the LS ground state as temperature increases. The reduced energy difference should enhance the quantum yield of the PIPT, even though the lifetime of the PI phase shortens with temperature.

\section{B. Initial stage of the photoinduced phase transition}

Now, let us proceed to the initial stage of the transient PIPT of the Co-Fe cyanide film. Figure 7 shows the differential absorption spectra of $\mathrm{Na}_{0.6} \mathrm{Co}_{1.3}\left[\mathrm{Fe}(\mathrm{CN})_{6}\right] \cdot 4 \mathrm{H}_{2} \mathrm{O}$ at $260 \mathrm{~K}$. At $\Delta t=30 \mathrm{~ns}$ (the lowest spectrum), we observed a photoinduced absorption band at $\approx 1.7 \mathrm{eV}$, as indicated by an upward arrow. Hereafter, we will call the absorption band " $Y$ band." The $Y$ band is observed only in the early state after the photoexcitation and almost disappears at $\Delta t=200 \mathrm{~ns}$.

In order to derive the precise temporal behavior of the $Y$ band, we decomposed the spectra into two Gauss components,

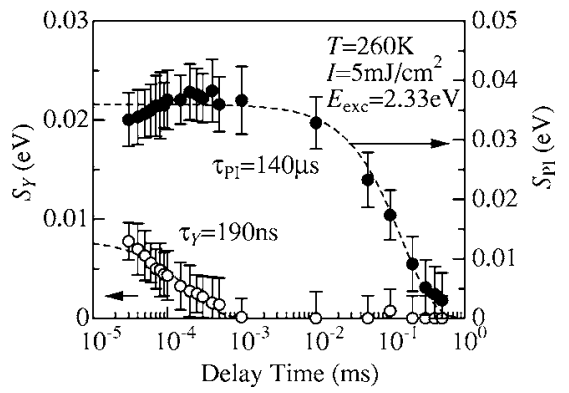

FIG. 8. Temporal behavior of the spectral weights of $\mathrm{Na}_{0.6} \mathrm{Co}_{1.3}\left[\mathrm{Fe}(\mathrm{CN})_{6}\right] \cdot 4 \mathrm{H}_{2} \mathrm{O}$ at $260 \mathrm{~K}$. Open circles represent the spectral weight $S_{Y}$ of the $Y$ band, whereas the filled circles does the spectral weight $S_{\mathrm{PI}}$ of the band due to the PI phase. Broken curves are the best-fitted result with exponential functions.

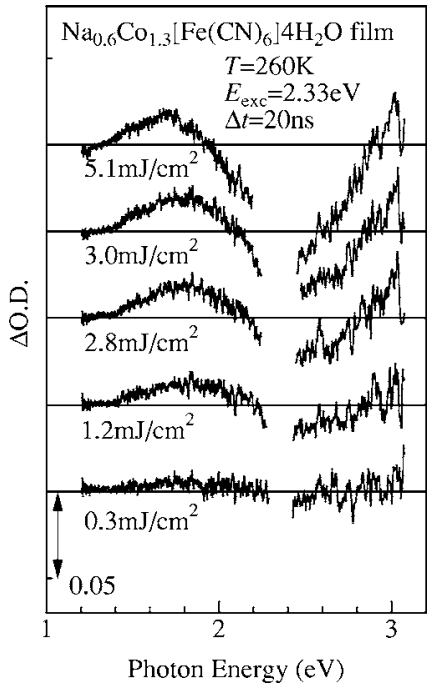

FIG. 9. Pulse energy dependence of differential absorption spectra of $\mathrm{Na}_{0.6} \mathrm{Co}_{1.3}\left[\mathrm{Fe}(\mathrm{CN})_{6}\right] \cdot 4 \mathrm{H}_{2} \mathrm{O}$ at $260 \mathrm{~K}$. The delay time $\Delta t$ was set at $20 \mathrm{~ns}$. The photon energy of the excitation light was $2.33 \mathrm{eV}$.

$$
\begin{aligned}
\Delta \text { O.D. }= & \frac{S_{Y}}{\sqrt{2 \pi}} \exp \left[-\frac{\left(\hbar \omega_{Y}-\hbar \omega\right)^{2}}{2 \Gamma_{Y}^{2}}\right] \\
& -\frac{S_{\mathrm{PI}}}{\sqrt{2 \pi}} \exp \left[-\frac{\left(\hbar \omega_{\mathrm{PI}}-\hbar \omega\right)^{2}}{2 \Gamma_{\mathrm{PI}}^{2}}\right],
\end{aligned}
$$

where the spectral weight, $S_{Y}$ and $S_{\mathrm{PI}}$, stand for the $Y$ band and the band due to the PI phase. Overall spectral profile was adjusted by the two parameters, $S_{Y}$ and $S_{\mathrm{PI}}$, and the other parameters are fixed as $\hbar \omega_{Y}=1.75 \mathrm{eV}, \hbar \omega_{\mathrm{PI}}=2.45 \mathrm{eV}, \Gamma_{Y}$ $=0.62 \mathrm{eV}$, and $\Gamma_{\mathrm{PI}}=0.77 \mathrm{eV}$. We shows in Fig. 8 the temporal behavior of the spectral weights of the $Y$ band (open circles) and the band (filled circles) due to the PI phase. Broken curves are the best-fitted-result with exponential functions. The lifetime $\tau_{Y}$ of the $Y$ band is $190 \mathrm{~ns}$, which is much faster than the lifetime $\tau_{\mathrm{PI}}(=140 \mu \mathrm{s})$ of the PI phase.

Figure 9 shows pulse energy dependence of the differential absorption spectra at $260 \mathrm{~K}$. We also decomposed the spectra into two Gauss components (see Eq. (1)) and plotted the results in Fig. 10. The magnitude of $S_{Y}$ linearly increases

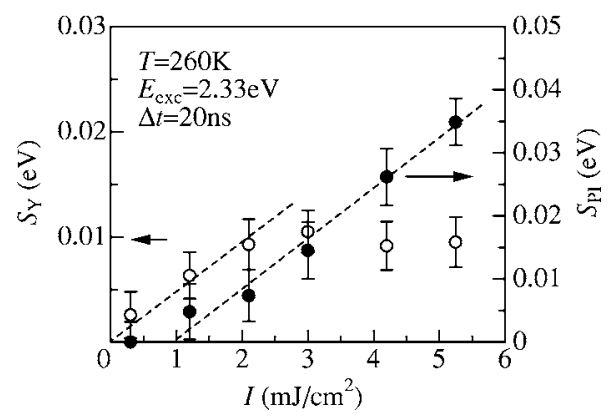

FIG. 10. Excitation energy $(I)$ dependence of the spectral weights of $\mathrm{Na}_{0.6} \mathrm{Co}_{1.3}\left[\mathrm{Fe}(\mathrm{CN})_{6}\right] \cdot 4 \mathrm{H}_{2} \mathrm{O}$ at $260 \mathrm{~K}$. Open circles represent the spectral weight $S_{Y}$ of the $Y$ band, whereas the filled circles represent the spectral weight $S_{\mathrm{PI}}$ of the band due to the PI phase. Broken lines are merely a guide to the eyes. 

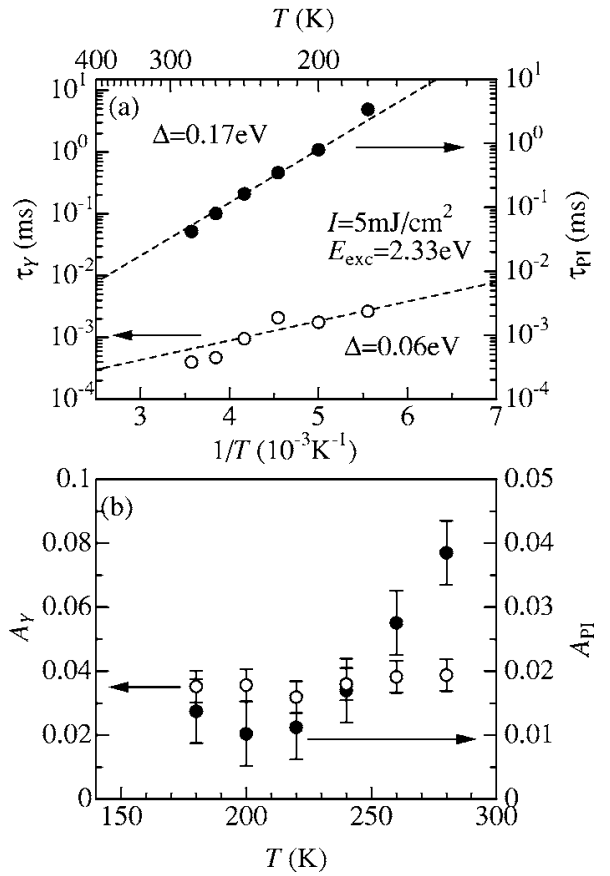

FIG. 11. Temperature dependence of (a) the lifetimes, $\tau_{Y}$ and $\tau_{\mathrm{PI}}$, and (b) the amplitudes, $A_{Y}$ and $A_{\mathrm{PI}}$. Open and filled circles are for the $Y$ band and the band due to the PI phase, respectively. A broken curve in (a) are the best-fitted result with exponential functions. The pulse energy and photon energy of the excitation light were $5 \mathrm{~mJ} / \mathrm{cm}^{2}$ and $2.33 \mathrm{eV}$, respectively.

as $I$ increase in the weak excitation region (see the broken line) and then is saturated when $I$ exceeds $\sim 2 \mathrm{~mJ} / \mathrm{cm}^{2}$. On the other hand, the magnitude of $S_{\mathrm{PI}}$ is rather suppressed in the weak excitation region, but steeply increases when $I$ exceeds $\sim 2 \mathrm{~mJ} / \mathrm{cm}^{2}$. Such a nonlinear (or threshold) behavior is frequently observed in the permanent PIPTs. ${ }^{8,12-15}$

In order to investigate the temperature-dependent behavior, we first measured the $\Delta T_{1.85 \mathrm{eV}}-\Delta t$ curve as a function of temperature. The obtained $\Delta T_{1.85} \mathrm{ev}^{-\Delta t}$ curves were analyzed by two exponential functions

$$
\Delta T_{1.85 \mathrm{eV}}=A_{Y} \exp \left(-\frac{\Delta t}{\tau_{Y}}\right)-A_{\mathrm{PI}} \exp \left(-\frac{\Delta t}{\tau_{\mathrm{PI}}}\right) .
$$

The former and the latter terms correspond to the $Y$ band and the band due to the PI phase, respectively. The best-fitted results are shown in Fig. 11: (a) the lifetimes, $\tau_{Y}$ and $\tau_{\mathrm{PI}}$, and (b) the amplitudes, $A_{Y}$ and $A_{\mathrm{PI}}$. The lifetime $\tau_{Y}$ [open circles in Fig. 11(a)] of the $Y$ band show rather gradual temperature dependence, as compared to $\tau_{\text {PI }}$ (filled circles). The activation energy $\Delta(\approx 0.06 \mathrm{eV})$ of $\tau_{Y}$ is much smaller than that $(\approx 0.17 \mathrm{eV})$ of $\tau_{\mathrm{PI}}$. On the other hand, amplitude $A_{Y}$ [open circles in Fig. 11(b)] of the $Y$ band is nearly independent of temperature, being in a sharp contrast to $A_{\mathrm{PI}}$ (filled circles).

Now, let us discuss the origin for the $Y$ band. The $Y$ band has the following characteristics: (1) the lifetime $\tau_{Y}$ exponentially increases as temperature decreases, (2) the signal intensity $S_{Y}$ linearly increases with the excitation energy $I$, and (3) the amplitude $A_{Y}$ is independent of temperature. These characteristics suggest that the $Y$ band is due to some self-trapped excited state. The most plausible candidate for the state is the LS Co ${ }^{2+}$ state $\left(t_{2 \mathrm{~g} \uparrow}^{3} t_{2 \mathrm{~g} \downarrow}^{3} e_{\mathrm{g} \uparrow}^{1}\right)$, which is the intermediate state for the PIPT of the Co-Fe cyanide. The magnitude of $\tau_{Y}$ $(\sim 100 \mathrm{~ns})$ is reasonable for such a state because the subsequent intersystem crossing into the $\mathrm{HS} \mathrm{Co}^{2+}\left(t_{2 \mathrm{~g} \uparrow}^{3} t_{2 \mathrm{~g} \downarrow}^{2} e_{\mathrm{g} \uparrow}^{2}\right)$ state would take a finite time. In addition, the transition energy $(\approx 1.7 \mathrm{eV})$ of the $Y$ band can be explained as follows. With the self-trapped $\mathrm{LS} \mathrm{Co}^{2+}$ state, one may expect the additional $t_{2 \mathrm{~g} \uparrow}^{3} t_{2 \mathrm{~g} \downarrow}^{3} e_{\mathrm{g} \uparrow \uparrow}^{1} t_{2 \mathrm{~g} \uparrow}^{2} t_{2 \mathrm{~g}\rfloor}^{3} e_{\mathrm{g} \uparrow}^{2}$ optical transition, whose transition energy is roughly the same as the ligand-field splitting of the $\left[\mathrm{Co}^{2+}(\mathrm{NC})_{6}\right]$ complex. Then, the observed transition energy $(\approx 1.7 \mathrm{eV})$ is reasonable, because the ligand-field splitting of the $\left[\mathrm{Co}^{2+}(\mathrm{NC})_{6}\right]$ complex should be larger than that $[=1.04 \mathrm{eV}$ (Ref. 26) $]$ of the $\left[\mathrm{Co}^{2+}\left(\mathrm{H}_{2} \mathrm{O}\right)_{6}\right]$ complex.

\section{SUMMARY}

In summary, we have investigated the dynamical behavior of PIPT of the Co-Fe cyanide film, $\mathrm{Na}_{0.6} \mathrm{Co}_{1.3}\left[\mathrm{Fe}(\mathrm{CN})_{6}\right] \cdot 4 \mathrm{H}_{2} \mathrm{O}$, by means of the transient absorption spectroscopy. Based on the experimental observations, we have proposed the following process for the transient PIPT. First, the photoexcitation induces the charge transfer from the LS $\mathrm{Fe}^{2+}\left(t_{2 \mathrm{~g}}^{3} t_{2 \mathrm{~g} \downarrow}^{3}\right)$ site to the LS $\mathrm{Co}^{3+}$ $\left(t_{2 \mathrm{~g} \uparrow}^{3} t_{2 \mathrm{~g} \downarrow}^{3}\right)$ site. Immediately after the photoexcitation, the photo created LS Co ${ }^{2+}\left(t_{2 \mathrm{~g} \uparrow}^{3} t_{2 \mathrm{~g} \downarrow}^{3} e_{\mathrm{g} \uparrow}^{1}\right)$ state causes the $Y$ band, whose lifetime $\tau_{Y}$ is order of $100 \mathrm{~ns}$. Then, the $\mathrm{LS} \mathrm{Co}^{2+}$ state relaxes into the $\mathrm{HS} \mathrm{Co}^{2+}\left(t_{2 \mathrm{~g} \uparrow}^{3} t_{2 \mathrm{~g} \downarrow}^{2} e_{\mathrm{g} \uparrow}^{2}\right)$ via the intersystem crossing process to cause the macroscopic HS phase.

\section{ACKNOWLEDGMENTS}

This work was supported by a Grant-In-Aid for Scientific Research from the Ministry of Education, Couture, Sports, Science and Technology and Mitsubishi Foundation.
*Author to whom correspondence should be addressed.

${ }^{1}$ Relaxzation of Exited States and Photoinduced Structural Transitions, edited by K. Nasu (Springer-Verlag, Berlin, 1977).

${ }^{2}$ J. Kusz, H. Spiering, and P. Gütlich, J. Appl. Crystallogr. 33, 201 (2000).

${ }^{3}$ J. Kusz, H. Spiering, and P. Gütlich, J. Appl. Crystallogr. 34, 229 (2001).
${ }^{4}$ M. Marchivie, P. Guionneau, J. A. K. Howard, G. Chastanet, J. F. Létard, A. E. Goeta, and D. Chasseau, J. Am. Chem. Soc. 124, 194 (2002).

${ }^{5}$ N. Huby, L. Guérin, E. Collet, L. Toupet, J.-C. Ameline, and H. Cailleau, T. Roisnel, T. Tayagaki, and K. Tanaka, Phys. Rev. B 69, 020101(R) (2004).

${ }^{6}$ O. Sato, T. Iyoda, A. Fujishima, and K. Hashimoto, Science 272, 
704 (1996).

${ }^{7}$ O. Sato, Y. Einaga, A. Fujishima, and K. Hashimoto, Inorg. Chem. 38, 4405 (1999).

${ }^{8}$ H. Tokoro, T. Matsuda, K. Hashimoto, and S. Ohkoshi, J. Appl. Phys. 97, 10M5083 (2005).

${ }^{9}$ Y. Moritomo, M. Hanawa, Y. Ohishi, K. Kato, M. Takata, A. Kuriki, E. Nishibori, M. Sakata, S. Ohkoshi, H. Tokoro, and K. Hashimoto, Phys. Rev. B 68, 144106 (2003).

${ }^{10}$ M. Hanawa, Y. Moritomo, A. Kuriki, J. Tateishi, K. Kato, M. Takata, and M. Sakata, J. Phys. Soc. Jpn. 72, 987 (2003).

${ }^{11}$ N. Shimamoto, S. Ohkoshi, O. Sato, and K. Hashimoto, Inorg. Chem. 41, 678 (2002).

${ }^{12}$ X. J. Liu, Y. Moritomo, M. Ichida, A. Nakamura, and N. Kojima, Phys. Rev. B 61, 20-23 (2000).

${ }^{13}$ H. Matsuzaki, T. Matsuoka, H. Kishida, K. Takizawa, H. Miyasaka, K. Sugiura, M. Yamashita, and H. Okamoto, Phys. Rev. Lett. 90, 046401 (2003).

${ }^{14}$ H. Matsuzaki, W. Fujita, K. Awaga, and H. Okamoto, Phys. Rev. Lett. 91, 017403 (2003).

${ }^{15}$ S. Koshihara, Y. Tokura, K. Takeda, and T. Koda, Phys. Rev. Lett. 68, 1148 (1992).

${ }^{16}$ E. Collet, M-H. Lemee-Cailleau, M. Buron-Le Cointe, H. Cailleau, M. Wulff, T. Luty, S. Koshihara, M. Meyer, L. Toupet, P. Rabiller, and S. Techert, Science 300, 612 (2003).
${ }^{17}$ The spectrum of the HT phase was for the as-grown film. The film is found to deteriorate above $320 \mathrm{~K}$, which prevents us from measuring the spectrum of the thermaly induced HT phase.

${ }^{18}$ Y. Sato, S. Ohkoshi, and K. Hashimoto, J. Appl. Phys. 92, 4834 (2002).

${ }^{19}$ Z. Gao, G. Wang, P. Li, and Z. Zhao, Electrochim. Acta 36, 147 (1991).

${ }^{20}$ O. Sato, Y. Einaga, T. Iyoda, A. Fujishima, and K. Hashimoto, J. Electrochem. Soc. 144, L11 (1991).

${ }^{21}$ H. J. Buser, D. Schwarzenbach, W. Petter, and A. Ludi, Inorg. Chem. 16, 2704 (1977).

${ }^{22}$ We have accumulated the database between the chemical composition and the transition temperatures in the Ns-Co- $\left[\mathrm{Fe}(\mathrm{CN})_{6}\right]-$ $\mathrm{H}_{2} \mathrm{O}$ systems, which enables us to roughly estimate the chemical composition from the transition temperature.

${ }^{23}$ The lifetime $\tau_{\text {PI }}$ of the PI phase shows slight sample dependence. This is perhaps due to the different thickness and/or grain size of the film.

${ }^{24}$ T. Kawamoto, Y. Asai, and S. Abe, Phys. Rev. Lett. 86, 348 (2001).

${ }^{25}$ H. Tokoro, S. Ohkoshi, T. Matsuda, and K. Hashimoto, Inorg. Chem. 43, 5231 (2004).

${ }^{26}$ Y. Tanabe and S. Sugano, J. Phys. Soc. Jpn. 9, 766 (1954). 